\title{
The Prospering of Macromolecular Materials Based on Plant Oils Within the Blooming Field of Polymers from Renewable Resources ${ }^{+}$
}

\author{
Alessandro Gandini ${ }^{1, *}$ and Talita Martins Lacerda ${ }^{2}$ \\ 1 Department, University Grenoble Alpes, LGP2, F-38000 Grenoble, France \\ 2 Biotechnology Department, Lorena School of Engineering, University of São Paulo, \\ CEP 12602-810 Lorena, SP, Brazil; talitalacerda@usp.br \\ * Correspondence: agandini@iqsc.usp.br \\ + Presented at the First International Conference on "Green" Polymer Materials 2020, 5-25 November 2020; \\ Available online: https://cgpm2020.sciforum.net/.
}

Published: 4 November 2020

\begin{abstract}
This paper provides an overview of the recent progress in research and development dealing with polymers derived from plant oils. It highlights the widening interest in novel approaches to the synthesis, characterization and properties of these materials from renewable resources and emphasizes their growing impact in sustainable macromolecular science and technology. The monomers used include unmodified triglycerides, their fatty acids or the corresponding esters, and chemically modified triglycerides and fatty acid esters. Comonomers include styrene, divinylbenzene, acrylics, furan derivatives, epoxides, etc. The synthetic pathways adopted for the preparation of these materials are very varied, going from traditional free radical and cationic polymerizations to polycondensation reactions, as well as metatheses and Diels-Alder syntheses. In addition to this general appraisal, the specific topic of the use of tung oil as a source of original polymers, copolymers and nanocomposites is discussed in greater details in terms of mechanisms, structures, properties and possible applications.
\end{abstract}

Keywords: polymers from renewable resources; vegetable oils; triglycerides; fatty acids; copolymerization; tung oil

\section{Introduction}

The presence of polymers in all sectors of today's society is irreversible and has generated debates about the harmful consequences that they cause to the environment, such as greenhouse gas emissions and the production of incalculable amounts of waste. In this context, efforts have been directed, in both academic and industrial sectors, to the development of alternative renewable materials [1,2], with priority to those that have also potential to be recovered after use. The application of biological platforms for the synthesis of macromolecular materials is a very promising strategy, as it opens the way for the production of original polymers with reduced environmental impact. The development of new technologies for the production of macromolecular materials from renewable resources is now boosted by widespread discussions on how polymers should advance in a sustainable society based on a circular economy, considering environmental aspects at the same time as promoting an efficient conversion of resources and a correct and reduced disposal of wastes [3].

Monomers prepared from vegetable biomass can produce versatile polymers, and many of them are based on consolidated technologies or on those under advanced development, which is the case of biobased ethylene, ethylene glycol and terephthalic acid [4]. Vegetable oils and their derivatives are protagonists for the development of polymers from biomass [5-12]. Indeed, an exponencial 
behavior is observed when both the number of scientific publications using the keywords "polymers" and "vegetable oils" and their corresponding citations are plotted as a function of time considering only the last two decades (Figures 1 and 2), which is a convincing demonstration that the subject is far from being fully exploited.

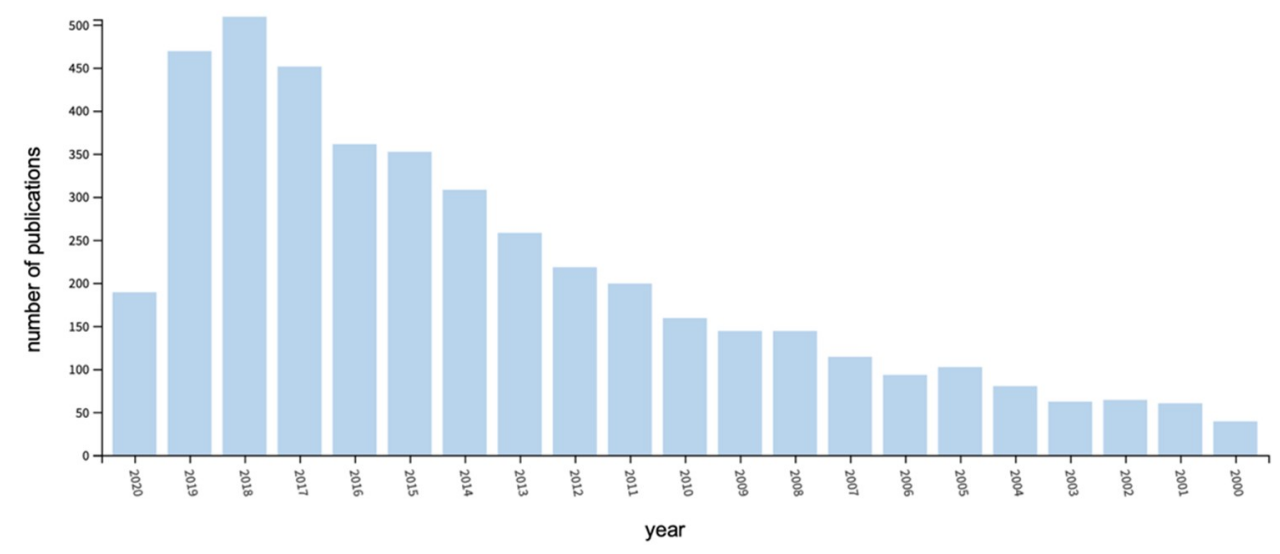

Figure 1. Number of yearly publications on polymers from vegetable oils [13].

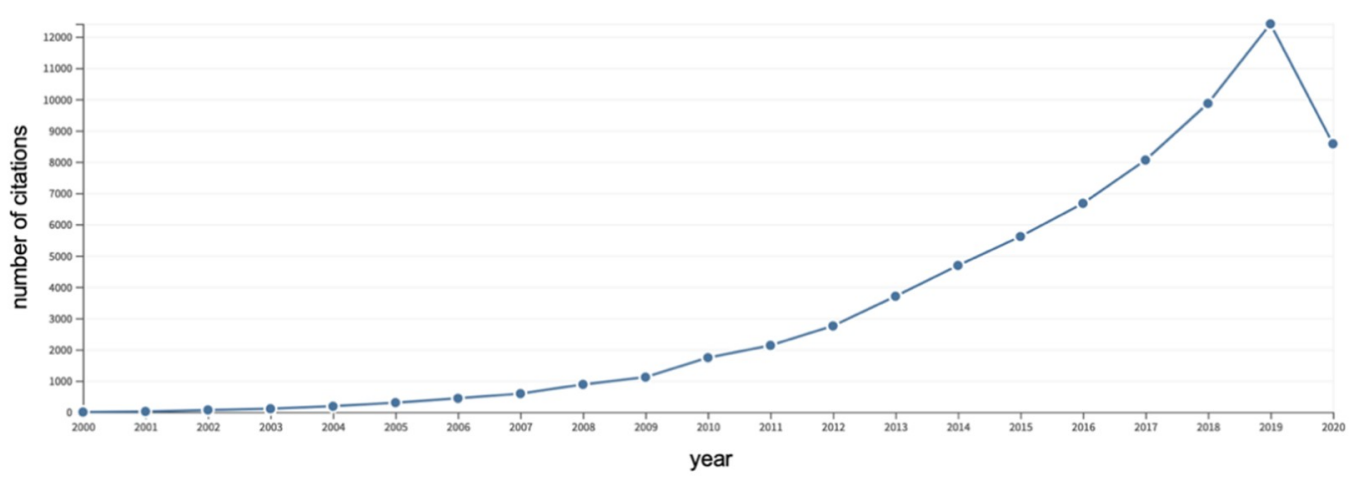

Figure 2. Number of yearly citations on polymers from vegetable oils [13].

To pursue novel polymers from vegetable oils, different approaches are possible, including, not exhaustively, the breakdown of triglycerides by transesterification processes and the chemical modification of the fatty acids' double bonds by means of metathesis, epoxidation and click reactions. The various possibilities in this regard lead to the production of polymeric materials with interesting properties and promising applications, such as thermosets, linear polyesters, polyurethanes, polyamides, and their blends and composites, among others.

This monograph aims to present an up-to-date overview of some important research strategies on the preparation of polymers from plant oils following a recent book on the topic [5], with a particular focus on novel synthetic approaches, as well as on original properties of the ensuing materials. First, the discussion focuses on the use of unmodified triglycerides as monomers, leading, on the one hand, to highly branched or crosslinked soft materials, or, on the other hand, to highly branched or crosslinked materials of higher $\mathrm{Tg}$ via their association with comonomers including styrene, divinylbenzene, acrylics, furan derivatives, etc. Then, attention is directed to the polymerization of fatty acids and the corresponding esters, and of other molecular structures derived from them. Finally, the specific use of tung oil and its main fatty acid as a source of original polymers, copolymers and nanocomposites is discussed in greater details in terms of mechanisms, structures, properties and possible applications. 


\section{Vegetable Oils: A Unique Source of Chemicals and Monomers}

Mostly extracted from the seeds of some species of annual plants, vegetable oils are viscous liquids at room temperature, always made up of a mixture of triglycerides bearing one or two predominant fatty acids. Their precise composition varies depending on the source from which the oil was extracted and edaphoclimatic factors. Linseed oil, for example, consists mainly of linoleic acid and linolenic acid, while in castor oil and tung oil, the most abundant fatty acids are, respectively, ricinoleic acid and $\alpha$-eleoestearic acid (Figure 3) [5,14]. According to the United States Department of Agriculture [15], the total production of major oilseeds around the world in 2019/2020 exceeded 577 Mt, with almost $60 \%$ consisting of soybean.

The main characteristics that determine the physicochemical properties of these oils are the stereochemistry of the double bonds, the degree of unsaturation and the length of the fatty acid chains. The average degree of unsaturation, measured by the iodine value (i.e., the amount of iodine (mg) that reacts with the double bonds of $100 \mathrm{~g}$ of a given oil), is particularly relevant in the present context, since the double bonds are the promoters of most of the functionalization, crosslinking and polymerization reactions. Iodine values of some common fatty acids and their triglycerides are given in Table 1.
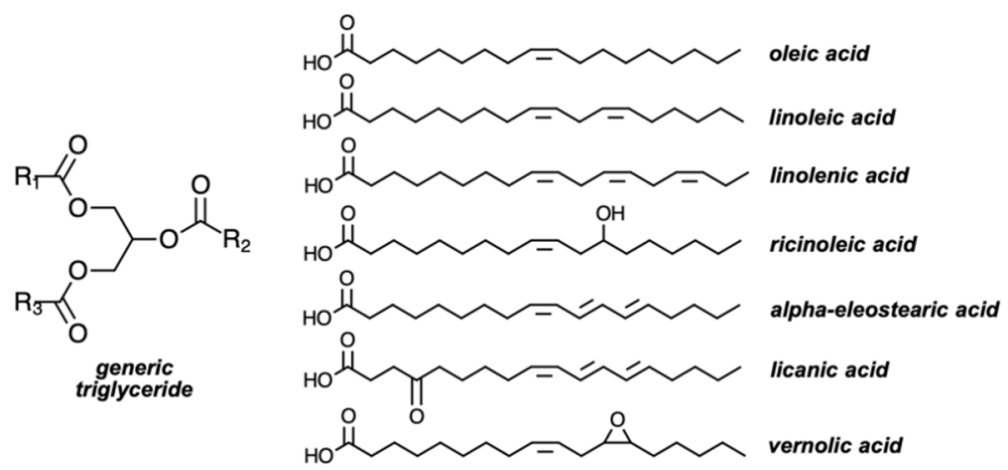

Figure 3. Molecular structure of a generic triglyceride and common unsaturated fatty acids present in the composition of vegetable oils.

Table 1. Iodine values of some unsaturated fatty acids and their triglycerides [5].

\begin{tabular}{ccc}
\hline \multirow{2}{*}{ Fatty Acid (Number of Carbon Atoms) } & \multicolumn{2}{|c}{ Iodine Value } \\
\cline { 2 - 3 } & Acid & Triglyceride \\
\hline Palmitoleic (C16) & 99.8 & 95 \\
Oleic (C18) & 89.9 & 86 \\
Linoleic (C18) & 181 & 173.2 \\
Linolenic (C18) and $\alpha$-eleostearic (C18) & 273.5 & 261.6 \\
Ricinoleic (C18) & 85.1 & 81.6 \\
Licanic (C18) & 261 & 258.6 \\
\hline
\end{tabular}

The large number of naturally available oils and the wide array of possible chemical modifications that can be performed are therefore the key that allow researchers to continuosly achieve a myriad of fascinating molecular structures based on triglycerides. In fact, oils and fats of vegetable and animal origin make up the greatest proportion of the consumption of renewable raw materials in the chemical industry [16]. The chemical modification of vegetable oils by means of oxidation, olefin metathesis, pericyclic reactions, radical additions, as well as transition-metal catalyzed and Diels-Alder syntheses to aromatic compounds are some of the many tools available to prepare chemicals of industrial interest that are not available from the fossil platform [17].

Considering the generic structure of a triglyceride incorporating $\mathrm{C}=\mathrm{C}$ unsaturations, the sites susceptible of undergoing reactions or chemical modifications are shown in Figure 4. More specific oils incorporating other functional groups such as hydroxyls or oxiranes offer additional sources of chemical exploitation. In industrial processing, vegetable oils are converted to glycerol plus fatty 
acids, methyl esters and fatty alcohols, and subsequent chemical modification steps are often conducted in order to obtain the specific chemicals of interest. Among these commodities, one finds, non-exhaustively, soaps, surfactants, emollients, pesticide formulations and lubricants [18]. Recently, "biodiesel" (fatty acid methyl esters, FAMEs) has emerged as a viable alternative in terms of renewable fuel, as produced from the basic-catalyzed transesterification of vegetable oils with methanol or ethanol.

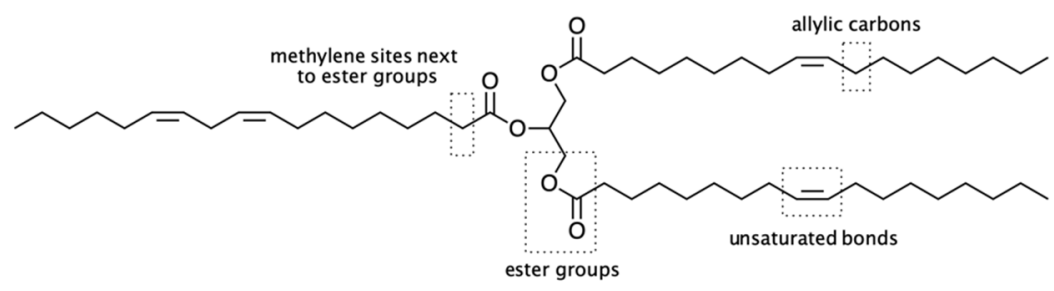

Figure 4. Four main reactive sites of unsaturated triglycerides.

This broad range of possibilities is also convenient to convert plant oils into a large variety of monomers and polymers. As a matter of fact, one can define some crude vegetable oils as natural oligomers, and film coatings based exclusively on unsaturated triglycerides have been used by man in different contexts. This is the case of tung oil, extracted from the seeds of Vernicia fordii nuts, which has a millennial history of exploitation in China as a siccative coating for waterproofing, varnishing, paints, lacquers and inks, thanks to the highly unsaturated structure of its main triglyceride, made up of $\alpha$-eleostearic fatty-acid motifs incorporating three conjugated double bonds (Figure 3). The mechanism of this "drying" process is based on the reaction of unsaturated moieties with atmospheric oxygen. In a first step, the $\mathrm{C}=\mathrm{C}$ double bonds activate de $\mathrm{C}-\mathrm{H}$ bonds of allylic carbons, upon which the oxygen molecule inserts itself to form a hydroperoxide molecule. The ensuing socalled oxido-polymerization reaction passes through the formation of radical intermediates, finally reaching a tridimensional network [5].

Since these first empirical exploitation, the strategy of converting plant oils into polymeric materials has vastly evolved, starting with linoleum, developed in the second half of the XIX century. Synthetic polymers based on vegetable oils have already been commercialized in large scale since the 1950s, with a nylon-11 based on castor oil (Arkema's Rilsan ${ }^{\circledR}$ ) as the main example. From then on, different synthetic routes, controlled processes and sophisticated catalysts are periodically reported, and today, vegetable oil-based polymeric materials with tunable properties can be designed according to the intended application. Among the possible approaches, one can emphasize the preparation of (i) highly branched and crosslinked materials, resulting from polymerization reactions of polyfunctional triglycerides, and (ii) linear materials, obtained by the breakdown of triglycerides into the corresponding fatty acids, which are often chemically modified to be converted into suitable bifunctional monomers. The most relevant contributions related to both strategies are briefly discussed below.

\section{Branched and Crosslinked Polymers Based on Pristine or Chemically Modified Tryglicerides}

The direct polymerization of polyfunctional vegetable oils into thermosets is a possibility that avoids preliminary synthetic steps and therefore represents a more sustainable approach towards polymeric materials [19]. The 1,2-disubstituted $\mathrm{C}=\mathrm{C}$ unsaturation of common fatty acids often reacts slowly in the presence of free radical and cationic initiators, and this strategy demands an association with a more reactive comonomer such as styrene and divinylbenzene [5]. A recent and very promising approach is based on the fact that sulfur can act as a monomer to initiate polymerization when heated to its molten state with unsaturated hydrocarbons. From this reaction emerged a new class of macromolecular materials called sulfur-based polymers, which are mostly prepared from fossil-based vinyl monomers. Unsaturated vegetable oils may serve as green and effective alternatives in this context, and the ensuing bio-based polymers (Figure 5) were synthesized and exhibited good potential for applications as cathode material in batteries such as Li-S batteries, as 
adsorbents for the removal of mercury and hydrocarbons from polluted water, and as support for smart controlled-release of fertilizers [20].

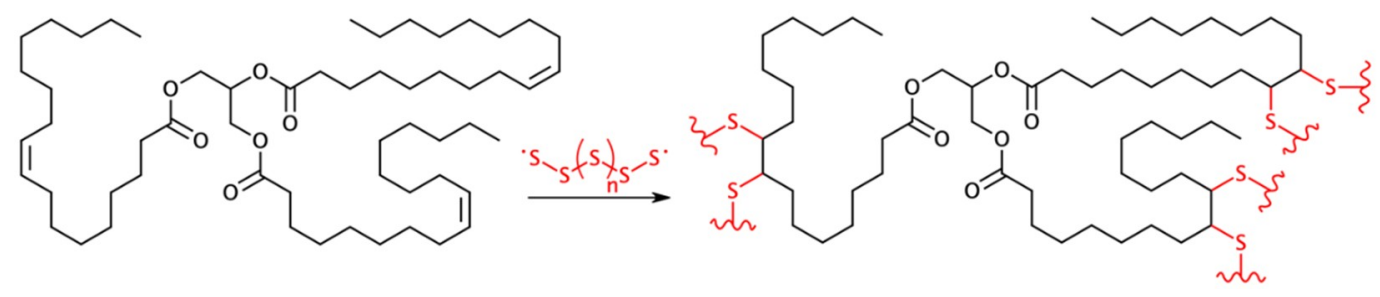

Figure 5. Schematic representation of a polymerization reaction between a triglyceride made up of oleic acid and elemental sulfur [20,21].

Despite the viability of directly polymerizing crude plant oils, a preliminary treatment for converting triglycerides into more reactive monomers is often convenient [5]. More recent contributions include a one-step acrylation procedure applied to palm oil, olive oil, peanut oil, rapeseed oil, corn oil, canola oil, and grapeseed oil, with the products separately mixed with polyurethane acrylate, trimethylolpropane triacrylate, and a photoinitiator to prepare ultravioletcurable films [22]. Epoxidation is another suitable preliminary reaction for the insertion of acrylic moieties into the triglyceride backbone, which was the route adopted to prepare acrylated linseed oil and, in a further step, aza-Michael polymers using priamine 1071, amine terminated poly(propyleneoxide)s (jeffamines) and meta-xylylenediamine as crosslinkers [23]. In another vein, castor oil was submitted to a two-step procedure of maleinization and methacrylation (using, respectively, maleic anhydride and glycidyl methacrylate) to synthesize a highly unsaturated monomer to be further homopolymerized and copolymerized in association with styrene [24]. The final materials were submitted to accelerated weathering tests in order to estimate their long-term performance under environmental conditions. Besides acting as a direct crosslinking agent for crude triglycerides, sulfur can also be useful for the synthesis of plant oil-based reactive monomers, since the thiol-ene click reaction may be applied as a versatile tool to yield high conversions under mild conditions. Diethyl allyl phosphonate A was inserted via the thiol-ene reaction into a commercial mercaptenized castor oil, and the ensuing polyol was used for the preparation of rigid polyurethanes with different weight percentages of phosphorus and with promising flame retardancy properties, ensuring fire safety for constructional and household applications [25].

In fact, the preparation of polyurethanes from vegetable oils is a subject that deserves attention, since its first report in the literature in the early 1990s [26], related to the preparation of polyurethane foams by mixing waste oil and polypropylene glycol with diphenylmethane diisocyanate, opened the way to hundreds of other publications belonging to the same field. Interesting and thorough monographs tackling the most relevant advances were recently published, calling upon aspects of synthesis, mechanical and thermal properties of polyurethanes from seed oil-based polyols [27], opportunities and challenges of bio-based polyurethanes with flame retardancy [28], as well as plant oil-based waterborne polyurethanes [8], viz. ionic and non-ionic polyurethane dispersions prepared in aqueous media. The materials are therefore evolving to more complex systems with specific applications, which is notably the case of the synthesis of vegetable oil-based polyurethanes for tissue engineering [29]. In this study, the thermosets exhibited good cytocompatibility and efficient antimicrobial activity against various microbial strains, and were considered suitable for wound dressing applications. The environmental concern of the whole process is also a major challenge regarding polyurethanes, and research has also focused on preparing VO-based non-volatile polyisocyanates, thus combining safety and renewable resources [5]. An additional green connotation was also added to vegetable oil-thermosets by associating monomers prepared from high oleic soybean oil and lignin. Azide-functionalized soybean oil polymers were prepared and submitted to click crosslinking with alkyne-modified lignin via metal-free thermal azide-alkyne cycloaddition reaction, leading to the preparation of elastomers consisting in a network of long flexible polymer chains [30]. The three-dimensional character of the final materials in this particular 
study was given by the polyfunctional nature of lignin, as the triglyceride itself was converted, in a first step, to its corresponding fatty esters by transesterification with 2-(methylamino)ethanol. Considering the utilization of vegetable oils as platform for the design of original macromolecular materials, hydrolysis and transesterification reactions are, however, more frequently conducted for the preparation of thermoplastic materials, as discussed below.

\section{Linear Polymers Based on Fatty Acids or Their Ensuing Derivatives}

The concept of producing linear polycondensates from plant oils has changed drastically in the past 70 years. The discreet example of Rilsan ${ }^{\circledR}$ has evolved into the utilization of vegetable oils as main components of sophisticated materials based on synthetic processes for the design of polymers with very specific applications [5]. The market for polyolefins is increasing yearly, which motivates the search for novel sources of monomers and polymers with original properties as emphasized by very recent research. Lomège and coworkers recently presented a very complete review covering the possible routes to convert fatty-acid based monomers into polymers via radical polymerization [12]. This monograph brings to light many examples of polyolefins that can be easily prepared from vegetable oils, with the most diverse type of pendant groups along the polymer chain. Other recent contribution is related to the preparation of ABA triblock copolyolefins from lauryl acrylate and triacetic acid lactone, leading to materials that are suitable for high-performance pressure-sensitive adhesives [31]. Isomerizing copolymerization was used to copolymerize high-oleic plant oils or fatty acid methyl esters with ethylene in a one-pot reaction [32]. The polyolefins were isolated with $\mathrm{Mn}$ values higher than $30 \mathrm{kDa}$, comprising more than 20 weight percent of plant oils. A very interesting strategy recently reported the synthesis of 8-heptadecadiene from oleic acid, and its subsequent polymerization produced isotatic and atatic polyolefins (Figure 6). The unsaturated pendant groups allowed to conduct a further step of post-polymerization crosslinking [33], as well as postpolymerization chemical modifications, such as bromination, epoxidation and cross-metathesis [34].

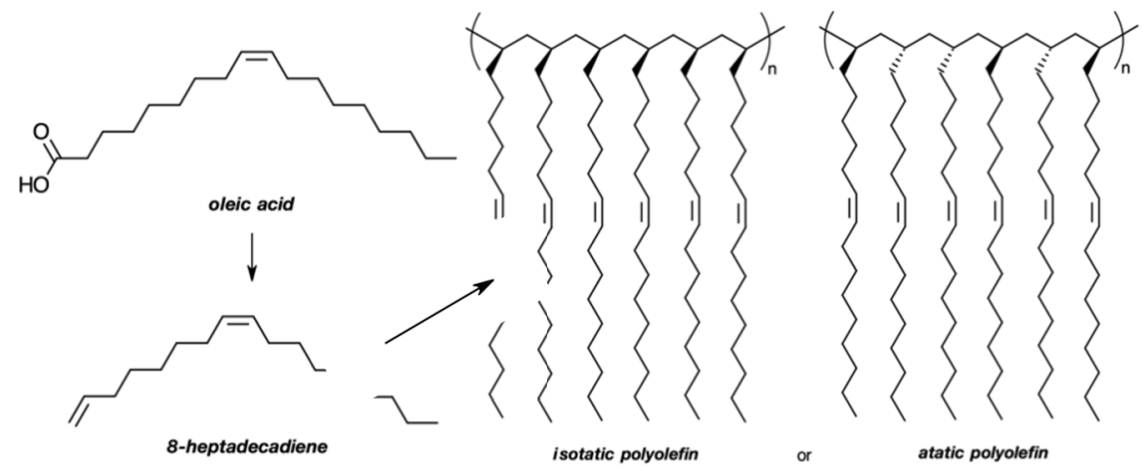

Figure 6. Schematic representation of the conversion of oleic acid into polyolefins [33].

The catalytic conversion of unsaturated fatty acids by isomerizing carbonylation or olefin metathesis yields (ultra)long-chain AB-type monomers bearing terminal dicarboxyl, diol or diamine groups [35]. These vegetable oil-based monomers can be polymerized to polyesters, polycarbonates and other (ultra)long-chain polycondensates, corresponding to polyethylene-like materials with an additional non-persistent nature. In fact, the synthesis of novel linear polyesters based on the vegetable oil platform is of great interest, with many promising contributions available in the literature. The castor oil-derived undecenol was submitted to catalytic functionalization/polymerization, yielding an aliphatic polyester in a single step procedure under mild conditions [36]. Unsaturated polyesters were prepared through cross-metathesis of oleic acid and oleic alcohol [37], and elastomeric copolyesters were synthesized from fatty acid diol monomers obtained from the reaction of stearic, oleic, linoleic acid and 7-hydroxy-4-methyl coumarin with diethanolamine [38]. Polyesters prepared from microalgae oil lipids have also been described [39].

Less frequent, but also of great interest, is the design of polyamides and polycarbonates from vegetable oils. A series of polyamide 11 copolymers was synthesized via melt polycondensation from 
11-aminoundecanoic acid, hexamethylene diamine, and a dimer acid obtained from unsaturated fatty acids through an acid-catalyzed Diels-Alder reaction [40]. The thermal and mechanical properties could be tuned by increasing the amount of dimer acid incorporated into the polyamide, as it increased the chain irregularity and therefore reduced the hydrogen bonding strength of the amide groups. A very interesting approach for the synthesis of polycarbonates was reported by Cramail's group, based on the controlled polymerization of a fatty acid-based cyclic carbonate bearing an unsaturation. The linear polymer was grafted with thio-cinnamate, a photo-sensitive moiety that allowed the material to form crosslinks when irradiated with a UV light at $365 \mathrm{~nm}$, and to return to its linear form when the wavelength was reduced to $254 \mathrm{~nm}$ [41]. The preparation of polycarbonates is particularly advantageous when carbon dioxide is used as raw material, and this strategy was reviewed considering also the utilization of other biobased feedstocks, such as plant oils, glycerol and fatty acids [42]. This is particularly promising in terms of green chemistry and sustainable development.

\section{The Case of Tung Oil: An Old Ally for Original Materials}

In the last decades, due to its low price, large availability, and peculiar chemical structure, the large exploitation of tung oil in different contexts can be considered a strong indication of its high potential to act as a rich source of molecules for the production of energy and materials. As a nonedible vegetable oil, it may be easily incorporated to the biodiesel industry without impacting the food and feed supply chain, leading to fatty acid methyl esters that met the ASTM quality standards of kinematic viscosity at $40^{\circ} \mathrm{C}$, density at $25^{\circ} \mathrm{C}$, clound point and pour point [43]. The use of tung oil for the synthesis of polymers is, however, much more promising in terms of the possibilities to develop smart functional materials that can be useful for a wide domain of applications.

The most classic attribution of tung oil, refering to centuries ago when men first coated wooden objects to improve its properties and to waterproof ships, is still an object of study. Researchers closely assessed the benefits of incorporating tung oil for the treatment of wood, which led to materials of improved dimensional stability, moisture absorption, thermal stability and morphological characteristic, which encouraged its implementation in buildings, furniture, and landscape architecture to broadly expand the application of wood products [44]. In this and other related cases, the ease with which tung oil is converted to a surface-dry film is given by its prompt susceptibility to the radicalar oxydopolymerization reaction, a process that cannot be avoided in the presence of oxygen. In fact, due to the possible formation of stable conjugated radical intermediates, tung oil can be homo- and copolymerized, in a strategy that was first described in the late 1960s and again in the early 1980s [45]. The most recent contributions consider a prior chemical modification of tung oil with acrylic and methacrylic moieties, leading to materials of superior thermal and mechanical properties, readly cured by UV light $[46,47]$. A more original strategy called upon the copolymerization reaction of crude tung oil and furfuryl methacrylate under inhert atmosphere, initiated by benzoyl peroxide, and the final networks were obtained in a second step based on the Diels-Alder click reaction between pendant furan moieties and residual conjugated double bonds of tung oil, which was performed under high pressure and high temperature [48].

The cationic homo- and copolymerization of tung oil is sporadically explored in the literature, in a strategy that was first reported by Larock's group in 2000 [45] and followed by a series of related works aiming to convert tung oil into three-dimensional networks, mostly using boron trifluoride diethyl etherate as initiator as well as other comonomers such as styrene, divinylbenzene, methyl $\alpha$ eleostearate, terpenes and poly(caprolactone) [2,5]. In all cases, no detailed mechanisms for the processes were put forward and most studies were carried out in an atmospheric environment and called upon the use of high temperatures for the final setting phase, so that, inevitably, free radicals also intervened in the network formation. Given the lack of information on the cationic polymerization mechanism of tung oil, an investigation on this process was conducted using trifluoroacetic acid (TFA) as initiator, room temperature and inhert atmosphere, and although some insight could be gathered from the tung oil polymerization, the rapid formation of crosslinked materials hindered a deeper understanding of the mechanistic and structural issues. The methyl ester 
of $\alpha$-eleostearic acid was therefore selected to mimic tung oil in this context because its cationic polymerization proceeded without leading to crosslinked products, thus allowing its progress to be followed in a homogeneous medium, notably by NMR spectroscopy [49]. The idea evolved into a more complex system, based on the cationic copolymerization of furfuryl alcohol with tung oil, in order to combine the high intrinsic flexibility of the crosslinked tung oil polymers with the stiffness of the furfuryl alcohol resin, leading to fully biobased crosslinked materials with a tunable glass transition temperature [50]. Three approaches were investigated, also using TFA as initiator, viz. (i) combining crude tung oil and furfuryl alcohol, (ii) combining methyl $\alpha$-eleostearate and furfuryl alcohol, and (iii) polymerizing furfuryl $\alpha$-eleostearate as a single monomer from which an furfuryl/triene interpenetrating network could be generated. The polymerization reactions with varying TFA concentrations were followed by NMR spectroscopy, and it was possible to get valuable information on mechanistic aspects and product properties.

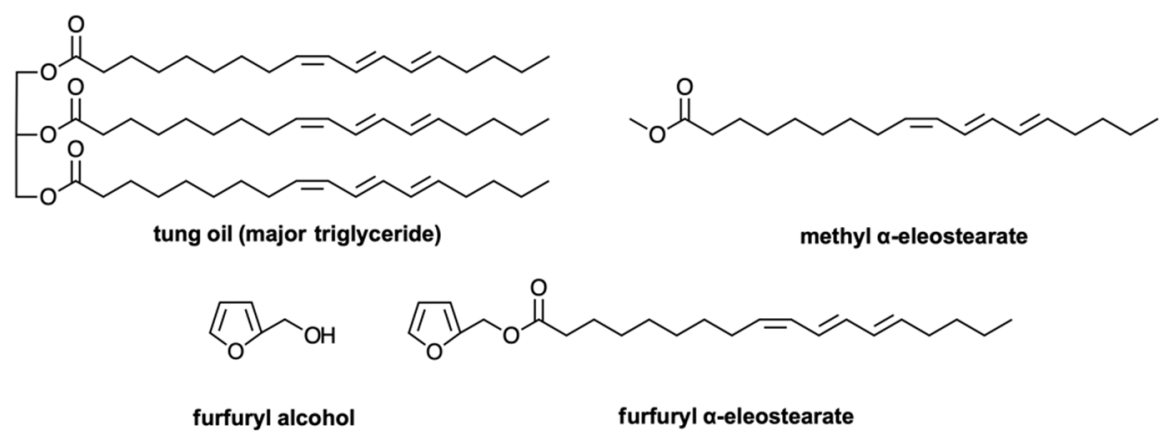

Figure 7. Monomers used for the preparation of tung oil/furfuryl alcohol networks [50].

Step-growth polymerization is also possible for the design of original tung-oil based polymers [5], and in this case, the prompt reactivity of the three conjugated double bonds of $\alpha$-eleostearic acid towards dienophiles in Diels-Alder click reactions if often explored to achieve this goal. Tung oil was submitted to two different reactions, viz. (i) the direct polymerization with bismaleimides for the synthesis of networks, and (ii) the bulk reaction with excess of furfurylamine, leading to the formation of an $\mathrm{AB}$ monomer containing a furan ring and the three conjugated double bonds of $\alpha$-eleostearic acid, to be further polymerized with bismaleimides [51]. More recently, the Diels-Alder reaction of tung oil with 4-maleimidophenol was conducted for the synthesis of polyols and, in a further step, of polyurethane elastomers [52]. Eleostearic diethanolamide was synthesized from tung oil and diethanolamine, and then reacted with hydroxymethylmaleimide to give a triol, which was mixed with castor oil and isophorone diisocyanate for the synthesis of polyurethanes [53].

The important number of investigations to convert tung oil into original macromolecular materials bodes well for the expectation of seeing it applied in a large scale in the near future, not only for the protection of wood products, but also to serve as platform for more sophisticated materials. 


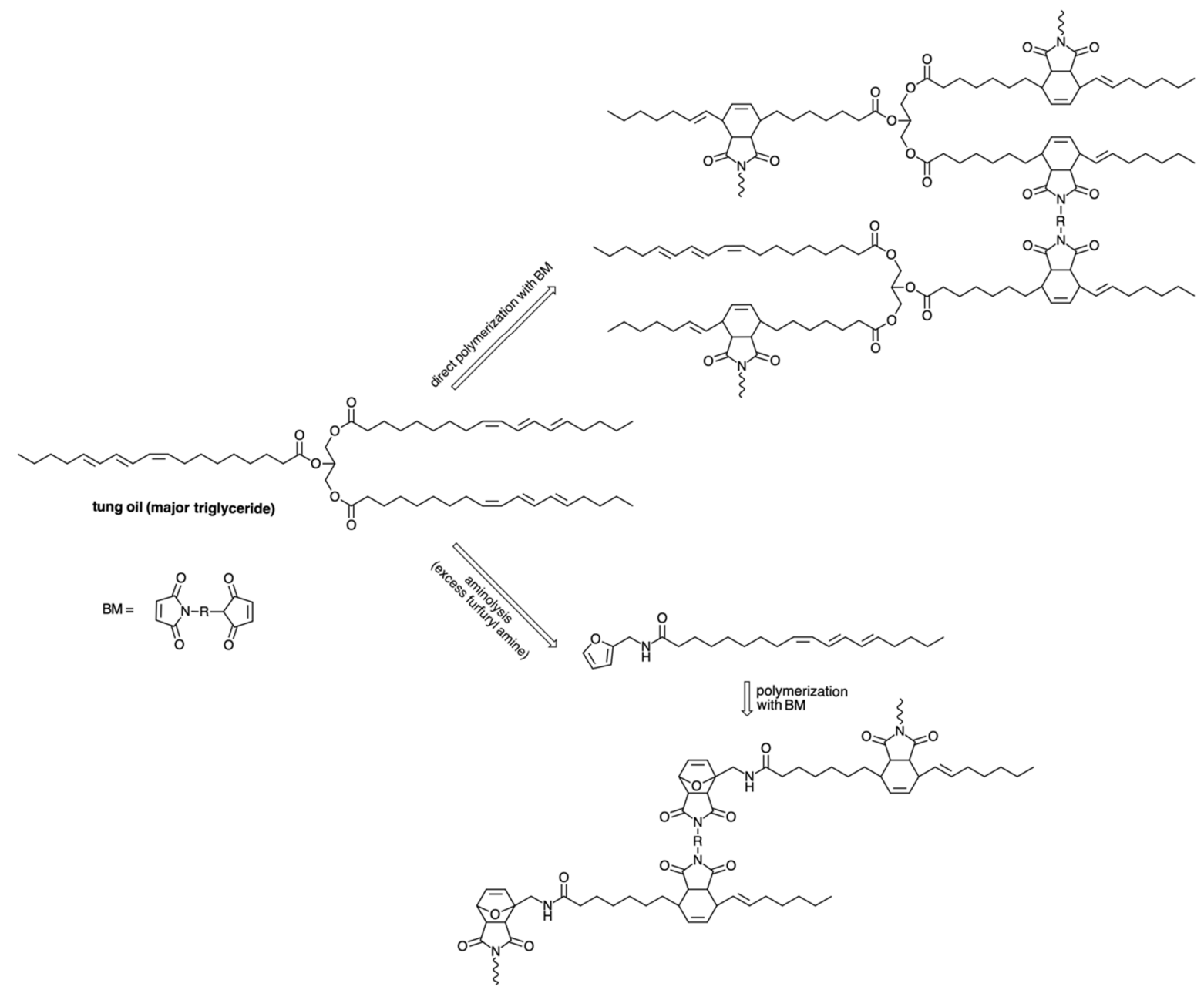

Figure 8. Schematic representation of the use of tung oil to produce Diels-Alder-based polymers [51].

\section{Conclusions}

The exploitation of vegetable oils has evolved radically during the last decades, and modern processes are now available to convert them into energy and materials. The latter strategy is particularly impressive, with promising ongoing research and development initiatives, indicating that this widely available renewable resource can now provide the basic building blocks of original and sophisticated macromolecular materials. The current scenario is expected to expand further, with plant oil-based polymers appearing more frequently as sources of commercial products capable of replacing important counterparts prepared from the fossil platform.

Author Contributions: A.G. and T.M.L. equally worked on the writing, reviewing and editing of the manuscript.

Acknowledgments: We thank FAPESP (São Paulo Research Foundation, Grants 2017/16062-6 and 2018/244076) for financial support.

Conflicts of Interest: The authors declare no conflict of interest.

\section{References}

1. Belgacem, M.N.; Gandini, A. Eds. Monomers Polymers and Composites from Renewable Resources; Elsevier: Amsterdam, The Netherlands, 2008; p. 552.

2. Gandini, A.; Lacerda, T.M. Polymers from Renewable Resources: Macromolecular Materials for the XXI Century? In Macromolecular Engineering: From Precise Synthesis to Macroscopic Materials and Applications, 2nd ed.; Gnanou, Y., Hadjichristidis, N., Matyjaszewski, K., Muthukumar, M., Sheiko, S., Wiley: 2020, in press. 
3. Kawashima, N.; Yagi, T.; Kojima, K. How do bioplastics and fossil-based plastics play in a circular economy? Macromol. Mater. Eng. 2019, 304, 1900383. doi:10.1002/mame.201900383.

4. Hillmyer, M.A. The promise of plastics from plants. Science 2017, 358, 868-870. doi:10.1126/science.aao6711.

5. Gandini, A.; Lacerda, T.M. Polymers from Plant Oils, 2nd ed.; John Wiley \& Sons and Scrivener Publishing: 2019.

6. Demchuk, Z.; Wu, N.; Pourhashem, G.; Voronov, A. Life cycle environmental impact considerations in the design of soybean oil-based acrylic monomers. ACS Sustain. Chem. Eng. 2020, 8, 12870-12876. doi:10.1021/acssuschemeng.0c03266.

7. Latif, F.E.A.; Abidin, Z.Z.; Cardona, F.; Biak, D.R.A.; Abdan, K.; Tahir, P.M; Ern, L.K. Bio-resin production through ethylene unsaturated carbon using vegetable oils. Processes 2020, 8, 48. doi:10.3390/pr8010048.

8. Mucci, V.L.; Hormaiztegui, M.E.V.; Aranguren, M.I. Plant oil-based waterborne polyurethanes: a brief review. J. Renew. Mater. 2020, 8, 579-601. doi:10.32604/jrm.2020.09455.

9. Carré, C.; Ecochard, Y.; Caillol, S.; Avérous, L. From the synthesis of biobased cyclic carbonate to polyhydroxyurethanes: a promising route towards renewable non-isocyanate polyurethanes. ChemSusChem 2019, 12, 3410-3430. doi:10.1002/cssc.201900737.

10. John, G.; Nagarajan, S.; Vemula, P.K.; Silverman, J.R.; Pillai, C.K.S. Natural monomers: A mine for functional and sustainable materials - Occurrence, chemical modification and polymerization. Progr. Polym. Sci. 2019, 92, 158-209. doi:10.1016/j.progpolymsci.2019.02.008.

11. Molina-Gutierrez, S.; Ladmiral, V.; Bongiovanni, R.; Caillol, S.; Lacroix-Desmazes, P. Radical polymerization of biobased monomers in aqueous dispersed media. Green Chem. 2019, 21, $36-53$. doi:10.1039/c8gc02277a.

12. Lomegè, J.; Lapinte, V.; Negrell, C.; Robin, J.-J.; Caillol, S. Fatty acid-based radically polymerizable monomers: from novel poly(meth)acrylates to cutting-edge properties. Biomacromolecules 2019, 20, 4-26. doi:10.1021/acs.biomac.8b01156.

13. Web of Science. Available online: www.webofknowledge.com (accessed on 8 September 2020).

14. Meier, M.A.R.; Metzger, J.O.; Schubert, U.S. Plant oil renewable resources as green alternatives in polymer science. Chem. Soc. Rev. 2007, 36, 1788-1802. doi:10.1039/B703294C.

15. United States Department of Agriculture (USDA). Available online: https://www.fas.usda.gov/psdonline/circulars/oilseeds.pdf (accessed on 24 September 2020).

16. Biermann, U.; Friedt, W.; Lang, S.; Lühs, W.; Machmüller, G.; Metzger, J.O.; Klaas, M.R.; Schäfer, H.J.; Schneider, M.P. New syntheses with oils and fats as renewable raw materials for the chemical industry. Angew. Chem. Int. Ed. 2000, 39, 2206-2224. doi:10.1002/1521-3773(20000703).

17. Biermann, U.; Bornscheuer, U.; Meier, M.A.R.; Metzger, J.O.; Schäfer, H.J. Oils and fats as renewable raw materials in chemistry. Angew. Chem. Int. Ed. 2011, 50, 3854-3871. doi:10.1002/anie.

18. Türünç, O.; Billiet, S.; Bruycker, K.; Ouardad, S.; Winne, J.; Du Prez, F.E. From plant oils to plant foils: Straightforward functionalization and crosslinking of natural plant oils with triazolinediones. Eur. Polym. J. 2015, 65, 286-297. doi:10.1016/j.eurpolymj.

19. Llevot, A. Sustainable synthetic approaches for the preparation of plant oil-based thermosets. J. Am. Oil Chem. Soc. 2017, 94, 169-186. doi:10.1007/s11746-016-2932-4.

20. Abbasi, A.; Nasef, M.M.; Yahya, W.Z.N. Copolymerization of vegetable oils and bio-based monomers with elemental sulfur: A new promising route for bio-based polymers. Sustain. Chem. Pharm. 2019, 13, 100158. doi:10.1016/j.scp.2019.100158.

21. Worthington, M.J.H.; Kucera, R.L.; Albuquerque, I.S.; Gibson, C.T.; Sibley, A.; Slattery, A.D.; Campbell, J.A.; Alboaiji, S.F.K.; Muller, K.A.; Young, J.; et al. Laying waste to mercury: inexpensive sorbents made from sulfur and recycled cooking oils. Chem. Eur. J. 2017, 23, 16219-16230. doi:10.1002/chem.201702871.

22. Su, Y.; Lin, H.; Zhang, S.; Yang, Z.; Yuan, T. One-step synthesis of novel renewable vegetable oil-based acrylate prepolymers and their application in UV-curable coatings. Polymers 2020, 12, 1165. doi:10.3390/polym12051165.

23. Ecochard, Y.; Auvergne, R.; Boutevin, B.; Caillol, S. Linseed oil-based thermosets by Aza-Michael polymerization. Eur. J. Lipid Sci. Technol. 2020, 122, 1900145. doi:10.1002/ejlt.201900145.

24. Echeverri, D.A.; Pérez, W.A.; Inciarte, H.C.; Rios, L.A. Accelerated weathering behavior of castor oil biobased thermosets. J. Appl. Polym. Sci. 2020, 137, e49509. doi:10.1002/app.49509. 
25. Bhoyate, S.; Ionescu, M.; Kahol, P.K.; Gupta, R.K. Castor-oil derived nonhalogenated reactive flameretardant-based polyurethane foams with significant reduced heat release rate. J. Appl. Polym. Sci. 2019, 136, 47276. doi:10.1002/APP.47276.

26. Nakamura, K.; Nishimura, Y. Polyurethane foam derived from waste vegetable oil. Kobunshi Ronbunshu 1993, 50, 881-886.

27. Ghasemlou, M.; Daver, F.; Ivanova, E.P.; Adhikari, B. Polyurethanes from seed oil-based polyols: A review of synthesis, mechanical and thermal properties. Ind. Crops Prod. 2019, 142, 111841. doi:10.1016/j.indcrop.

28. Vahabi, H.; Rastin, H.; Movahedifar, E.; Antoun, K.; Brosse, N.; Saeb, M.R. Flame retardancy of bio-based polyurethanes: opportunities and challenges. Polymers 2020, 12, 1234. doi:10.3390.

29. Gholami, H.; Yeganeh, H. Vegetable oil-based polyurethanes as antimicrobial wound dressings: in vitro and in vivo evaluation. Biomed. Mater. 2020, 15, 045001. doi:10.1088/1748-605X/ab7387.

30. Yuan, L.; Zhang, Y.; Wang, Z.; Han, Y.; Tang, C. Plant oil and lignin-derived elastomers via thermal azide-alkyne cycloaddition click chemistry. ACS Sustain. Chem. Eng. 2019, 7, $2593-2601$. doi:10.1021/acssuschemeng.8b05617.

31. Sajjad, H.; Tolman, W.B.; Reineke, T.M. Block copolymer pressure-sensitive adhesives derived from fatty acids and triacetic acid lactone. ACS Appl. Polym. Mater. 2020, 2, 2719-2728. doi:10.1021/acsapm.0c00317.

32. Fleckhaus, A.; Fokou, P.A.; Klaassen, G.; Klaas, M.R. One-pot catalytic copolymerization of unsaturated plant oils or fatty acid methyl esters with ethylene. Eur. J. Lipid Sci. Technol. 2019, 121, 1700429. doi:10.1002/ejlt.201700429.

33. Ohtake, K.; Onose, Y.; Kuwabara, J.; Kanbara, T. Synthesis and characterization of a thermally crosslinkable polyolefin from oleic acid. J. Polym. Sci. A1 2019, 57, 85-89. doi:10.1002/pola.29269.

34. Ohtake, K.; Onose, Y.; Kuwabara, J.; Kanbara, T. Postfunctionalization of reactive polyolefins derived from fatty acids. React. Funct. Polym. 2019, 139, 17-24. doi:10.1016/j.reactfunctpolym.

35. Mecking, S. Polyethylene-like materials from plant oils. Phil. Trans. R. Soc. A 2020, 378, 20190266. doi:10.1098/rsta.2019.0266.

36. Liu, Y.; Mecking, S. A synthetic polyester from plant oil feedstock by functionalizing polymerization. Angew. Chem. Int. Ed. 2019, 58, 3346-3350. doi:10.1002/anie.201810914.

37. Aguilar-Castro, C.; Gomez, M.D.; Nava, M.G.; García, J.M.R.; Uribe, L.E.L. Biobased polyester obtained from bifunctional monomers through metathesis of fatty acids as precursor to synthesis of polyurethanes. J. Appl. Polym. Sci. 2019, 136, 47095. doi:10.1002/app.47095.

38. Liu, X.; Jain, T.; Liu, Q.; Joy, A. Structural insight into the viscoelastic behaviour of elastomeric polyesters: effect of the nature of fatty acid side chains and the degree of unsaturation. Polym. Chem. 2020, 11, 52165224. doi:10.1039/d0py00457j.

39. Haia, T.A.P.; Neelakantan, N.; Tessman, M.; Sherman, S.; Griffin, G.; Pomeroy, R.S.; Mayfield, S.; Burkart, M. Flexible polyurethanes, renewable fuels, and flavorings from a microalgae oil waste stream. Green Chem. 2020, 22, 3088-3094. doi:10.1039/D0GC00852D.

40. Park, M.S.; Lee, S.; Kim, AR.; Choi, I.; Shin, J.; Kim, Y.-W. Toughened and hydrophobically modified polyamide 11 copolymers with dimer acids derived from waste vegetable oil. J. Appl. Polym. Sci. 2019, 136, 47174. doi:10.1002/APP.47174.

41. Durand, P.-L.; Bregè, A.; Chollet, G.; Grau, E.; Cramail, H. Simple and efficient approach toward photosensitive biobased aliphatic polycarbonate materials. ACS Macro Lett. 2018, 7, $250-254$. doi:10.1021/acsmacrolett.8b00003.

42. Cui, S.; Borgemenke, J.; Liu, Z.; Li, Y. Recent advances of "soft" bio-polycarbonate plastics from carbon dioxide and renewable bio-feedstocks via straightforward and innovative routes. J. $\mathrm{CO}_{2}$ Util. 2019, 34, 4052. doi:10.1016/j.jcou.2019.05.027.

43. Panchal, B.; Chang, T.; Qin, S.; Sun, Y.; Wang, J.; Bian, K. Optimization and kinetics of tung nut oil transesterification with methanol using novel solid acidic ionic liquid polymer as catalyst for methyl ester synthesis. Renew. Energ. 2020, 151, 796-804. Doi:10.1016/j.renene.2019.11.066.

44. He, Z.; Qiana, J.; Qua, L.; Yan, N.; Yi, S. Effects of Tung oil treatment on wood hygroscopicity, dimensional stability and thermostability. Ind. Crops Prod. 2019, 140, 111647. doi:10.1016/j.indcrop.2019.111647.

45. Li, F.; Larock, R.C. Thermosetting polymers from cationic copolymerization of tung oil: synthesis and characterization. J. Appl. Polym. Sci. 2000, 78, 1044-1056. doi:10.1002/1097-4628(20001031)78:5<1044::AIDAPP130>3.0.CO;2-A. 
46. Liang, B.; Zhao, J.; Li, G.; Huang, Y.; Yang, Z.; Yuan, T. Facile synthesis and characterization of novel multifunctional bio-based acrylate prepolymers derived from tung oil and its application in UV-curable coatings. Ind. Crops Prod. 2019, 138, 111585. doi:10.1016/j.indcrop.2019.111585.

47. Man, L.; Hu, Y.; Feng, Y.; Zhang, C.; Yuan, T.; Yang, Z. Facile synthesis of a novel bio-based methacrylate monomer derived from tung oil and its application for solvent-free thermosetting coatings. Ind. Crops Prod. 2019, 133, 348-356. doi:10.1016/j.indcrop.2019.03.047.

48. Sain, S.; Åkesson, D.; Skrifvars, M. Synthesis and properties of thermosets from tung oil and furfuryl methacrylate. Polymers 2020, 12, 258. doi:10.3390/polym12020258.

49. Lacerda, T.M.; Gandini, A. The cationic polymerization of tung oil and its fatty-acid methyl ester. Ind. Crops Prod. 2020, 157, 112886. doi:10.1016/j.indcrop.2020.112886.

50. Ribeiro, B.O.; Valério, V.S.; Gandini, A.; Lacerda, T.M. Copolymers of xylan-derived furfuryl alcohol and natural oligomeric tung oil derivatives. Int. J. Biol. Macromol. 2020, 164, 2497-2511. doi:10.1016/j.ijbiomac.2020.08.095.

51. Lacerda, T.M.; Carvalho, A.J.F.; Gandini, A. Two alternative approaches to the Diels-Alder polymerization of tung oil. RSC Adv. 2014, 4, 26829-26837. doi:10.1039/c4ra03416c.

52. Li, M.; Ding, H.; Yang, X.; Xu, L.; Xia, J.; Li, S. Preparation and properties of self-healing polyurethane elastomer derived from tung-oil-based polyphenol. ACS Omega 2020, 5, 529-536. doi:10.1021/acsomega.9b03082.

53. Feng, Y.; Man, L.; Hu, Y.; Chen, L.; Xie, B.; Zhang, C.; Yuan, T.; Yang, Z. One-pot synthesis of polyurethaneimides with tailored performance from castor and tung oil. Progr. Org. Coat. 2019, 132, 62-69. doi:10.1016/j.porgcoat.

Publisher's Note: MDPI stays neutral with regard to jurisdictional claims in published maps and institutional affiliations.

(C) 2020 by the authors. Submitted for possible open access publication under the terms and conditions of the Creative Commons Attribution (CC BY) license (http://creativecommons.org/licenses/by/4.0/). 